\title{
Cost of climate change underestimated
}

The global cost of adapting to climate change could be $2-3$ times higher than previously thought, says a study published on 27 August.

In 2007, the United Nations Framework Convention on Climate Change (UNFCCC). suggested that the annual cost of climate adaptation, starting in 2030, would be between US $\$ 49$ billion and $\$ 171$ billion. The new report says this estimate does not account for climate change's effects on key sectors such as energy, manufacturing, tourism and ecosystems.

The question of how to finance adaptation will be at the heart of December's negotiations in Copenhagen to forge an international climate deal to replace the Kyoto Protocol when it expires in 2012.

"There are dangers in having apparently low estimates for the cost of adaptation, which would make adaptation seem like a cheap alternative to mitigation," says the study's lead author Martin Parry, a visiting research fellow at the Grantham Institute for Climate

Change at Imperial College London.

The UNFCCC numbers were not intended to be the final word but rather a ball-park figure to get the negotiations rolling, says Sudhir Sharma, manager of financial cooperation and capacity building at the UNFCCC secretariat in Bonn, Germany. "We clearly indicated that this was not an exhaustive study," he says. "Our objective was to kick-start the process of

"There are dangers in having apparently low estimates for the cost of adaptation." that other groups could pick up the baton and refine them."

The latest work suggests that in the area of water management, the UNFCCC estimate of $\$ 11$ billion per year overlooks the expenses of floods and of transporting water from areas of plenty to areas in need. In health, the UNFCCC figure of $\$ 5$ billion per year considered changes only in malaria, diarrhoea and malnutrition in developing nations and not the health burden of cific cost estimates, however.

climate change in developed nations. The new report also notes that the UNFCCC estimates excluded the costs of protecting ecosystems and the services they provide. On its own this sector could cost well over $\$ 350$ billion per year, says Parry.

The report, published by the International Institute for Environment and Development in London and the Grantham Institute, does not provide spe-

Those may come shortly from other groups. In mid-September, the Economics of Climate Adaptation Working Group, a consortium of researchers, consultants and economists, will release a report on adaptation costs. And on 29 September the World Bank is expected to launch its own study in the area.

Anjali Nayar

For more climate coverage, see nature.com/ roadtocopenhagen 